\title{
Sports Companies' and Leagues' Data Utilization to Alleviate the Negative Influences Caused by the Pandemic
}

\author{
Tianqin Xia
}

Questrom School, Boston University, Massachusetts, 02215, the USA

Corresponding author.Email: gaoming@cas-harbour.org

\begin{abstract}
The sports industry has been severely hit by the pandemic. Games are postponed, and fans are not allowed to enter the stadium or arena. In such a serious situation, sports companies' and sports leagues' revenues shrink a lot, and they are keen on restoring and sustaining their business. In order to help them achieve the goal, the paper focuses on analyzing the problems and opportunities brought by the pandemic to the sports industry. Then based on the analysis, the paper offers recommendations for the sports companies and sports leagues to solve their problems. The research method of the paper is to collect and analyze different types of articles about the sports industry in the pandemic. Then the paper summarizes the key points from those articles and integrate them with the author's insights. According to the research results, to survive from the pandemic, the sports companies and sports leagues can attract more customers using data from digital platforms, combine data and technology to offer fans a novel watching experience, entering the sports gambling industry, which is eager for data, and record accurate data about players to ensure their health.
\end{abstract}

Keywords: Data utilization, sports industry, pandemic, digital platforms

\section{INTRODUCTION}

The sports industry has been hit severely by the pandemic. Because of the pandemic, people cannot go out to watch the games, and most of the sports events have been delayed. For example, the Tokyo 2020 Olympics Games and the European Football Championship

2020 have been delayed to 2021. Even some of the sports games have recovered, the organizers need to take the safety protocol seriously to protect the safety of the workers and players. For example, the National Basketball Association requires that "any player who tests positive, even if asymptomatic, will not be allowed to exercise for a minimum of 10 days and then must be monitored in individual workouts for an additional two days" [1]. Until now, many games still have to proceed without fan attendance. As a result, the revenues for sports companies and leagues have decreased dramatically during the pandemic. For example, the
National Football League has reported 4 billion dollars loss due to the pandemic [2]. In order to restore and continue their business during the pandemic, they need to come up with some innovative ideas. At this time, they can adopt the idea of data utilization to help them make informed and effective decisions.

Before using the data utilization to improve their performance, the sports companies should be aware of the context of the sports industry during the pandemic. The pandemic has brought both problems and opportunities to the sports companies and leagues. Based on the analysis of the problems and opportunities, they can utilize data to make effective decisions to restore and sustain their business.

\section{PROBLEMS}

When the pandemic appears at first, many players, workers, and customers are infected. The crowded space in the arena and stadium means a high chance of getting 
the virus. Thus, many leagues have to suspend their games. For example, the National Basketball Association, the Major League Baseball, and the Major League Soccer has suspended their games, concerning the spread of virus. The policy for quarantine in countries varies, making international games even harder to continue. For instance, the FISU World University Games 2021 has been delayed to 2022 due to the global COVID-19 situation and the international travel restrictions [3]. Those leagues and associations have to postpone their games until they reach an effective plan to continue the games.

Even when the games are resumed, fan attendance is not allowed by many leagues. And many of them decide that games will be played in a specific area. The mobility of players and workers to go out of the area is seriously controlled. For example, the NBA has decided to resume the games in a bubble in Orlando for the 2019-2020 season and restricts the face-to face communication with outsiders. What is more, in order to catch up with the required timeline for the next season or international competitions, some leagues decide to decrease the number of games. For example, the Major League Baseball has decided to shorten the number of games from 162 to 60 in the 2020 season [4].

The suspension of games can harm the relationship between fans and teams or players. The lack of games as a medium can impede the direct communication between them, and the fan engagement can be badly influenced. What is more, the suspension requires the leagues to adjust their contracts with sponsors to the new game plans. Playing in a specific area, decreasing the number of games, or banning fan attendance mean that the leagues will lose huge gate revenues from the games. For example, "MLS claims it lost nearly $\$ 1$ billion in revenue in 2020. This loss largely reflected an abridged 2020 season and reduced match-day attendance" [5].

The player's injury rate has been increased by higher frequency of games: to catch with the required timeline, some leagues increase the games per day. For example, in the NBA's 2020-2021 season, "the average number of players sidelined per game due to injury, non-COVID-19 illness or rest this season was 5.1 (includes both teams), according to ESPN's Kevin Pelton, the highest since he started tracking it in 2009-10" [6].

The confined environment can also harm the players' mental health. The unusual way of playing games and having mobility controlled makes them feel uncomfortable. For example. "the COVID-19 pandemic lockdown is a peculiar situation in which athletes had to be in isolation, away from their sport without any certainty of resumption or any form of real social support from relatives and friends. It might have led to feelings of sadness and hopelessness in some individual sports athletes" [7].

\section{OPPORTUNITIES}

As the pandemic keeps for a long time, people do not go out for meals or shopping. They do not buy the tickets to watch the game. Their disposable income tends to increase during the pandemic. It is estimated that "consumers in the world's largest economies amassed \$2.9 trillion in extra savings during Covid-related lockdowns" [8]. As the pandemic alleviates or continues, the customers will find new ways to spend their money. The sports companies and leagues are expected to compete for the disposable income through effective methods to sustain their business.

What is more, the pandemic has changed customers' behaviors. Due to the limitation on mobility and recreational activities, customers' way of life has changed gradually. Because of the decreasing number and no fan attendance of the games, they are willing to share their ideas on social platform about players or games. For example, "the recent Michael Jordan miniseries The Last Dance was the subject of over 1.5 million tweets during its finale episode, and the WWE's Wrestlemania scored a staggering 13.8 million social media engagements across all platforms in April" [9]. Moreover, since customers cannot go to the arena or stadium, they have adapted to watching the games through online live broadcast platform. For example, "much has been made of the fact that the majority of the Tokyo 2020 Olympic Games is only available in the U.K. on the Discovery+streaming platform, and a new study has suggested that nearly threequarters $(73 \%)$ of British sports fans want it that way" [10]. Those changes of customers' behaviors offer sports companies and leagues an opportunity to collect the information and data about the customers and use them to aid their decision-making.

Although the pandemic causes game suspension, the fans' enthusiasm for the games does not weaken. They still expect the game resumption after the leagues find a feasible plan. The fans' fervid attitude encourages sports companies to recover from the pandemic and leaves them a bright future of the sport industry.

Based on the discussions of problems and opportunities above, the recommendations for the sports companies and leagues are explained as the following. 


\section{RECOMMENDATION}

During the pandemic, customers get used to communicate their ideas through online social platforms, and many of them prefer watching the games through online live broadcast platforms. Those changes of customer behaviors offer sport companies an opportunity to know more about the customers and make sensible decisions to attract more of them. The sports companies can collect and analyze the data about the customer's preferences and habits on those types of digital platforms. For example, they can record the customers' frequency of sharing their ideas about certain player and what their attitudes towards a player or a game. By doing this, the sport companies can target the right customers and push personalized advertisements about their interested games or products to them. Customers will see attractive advertisements on those platforms and on other applications, and they are more likely to buy the related service or products, increasing the revenues of the sports companies. "Real Madrid's digital platform is a prime example of this. As a team which only has $3 \%$ of their fan base at home in Spain, the football club had already been using data and technology to tailor experiences for supporters abroad. Its virtual platform enabled the club to provide a more tailored experience for fans and has seen digital revenues increase by $30 \%$ and fan profiles increase by $400 \% "$ [11].

The sports companies and leagues can make the data about players more accessible to the fans, such as field goal percentages in different areas. At the same time, they can combine those data with new technology to offer fans a new watching experience. They can enable the fans to watch the game with the players' real-time efficiency rate shown on the screen, like what the Clippers CourtVision does. And the technology has kept improving. In the 2020 Tokyo Olympic Track and Field and Swimming Competition, the technology called 3DAT has been adopted. It has helpt show various data about the players such as the real-time position, real-time speed, acceleration, deceleration, and the distance among players to the spectators. The utilization of data mentioned above can help improve the fan engagement and attract more customers.

The sports gambling industry has emerged and developed fast. And the legalization of sports betting in many places and the pandemic has speeded up the development of this industry. The demand for data about sports is huge. And in different leagues, there is a huge amount of data about players and games. Thus, to earn more revenues, the leagues can cooperate with sports betting companies and sell the data to them. Or the leagues can even establish their sports betting companies, obtaining a new source of revenues. For example, "the NFL has inked a deal with Sportradar to distribute official league data to bookmakers in the U.S. and in other countries" [12]. Besides, "DraftKings, FanDuel, William Hill, MGM Resorts, Caesars Entertainment and Betstars are among gambling companies that have reached individual deals with leagues to buy their official data" [12]. At the same time, sports leagues can combine sports games with sports betting to engage more fans. For example, "NBA Digital offered fans a dozen 'NBA BetStream' telecasts this August via NBA TV and NBA League Pass. Presenting partner BetMGM provided realtime betting lines and stats" [13].

Due to the pandemic, many leagues have increased the frequency of games for each team. For example, "the Miami Heat, for their part, went 51 days (Jan. 13-March 4, 2021)-and played 27 games-without more than one day of rest between games, the longest such streak since the lockout-shortened 2011-12 season" [14]. For all the NBA teams, "the average number of games per week per team in the 2019-20 season was 3.42. The number increased to 3.6 in the 2020-21 season and has jumped to 3.75 post-All Star" [14]. This kind of competition frequency decreases players' rest time and increases competition intensity. Players' health is threatened, and the rate of injury increases. To mitigate the problem, the leagues can make more efforts to collect and analyze the data about players. They can establish database and keep focusing on data about the players' health during the pandemic, such as the potential rate of certain injury. Therefore, the players can keep healthy and carry on in the future.

\section{CONCLUSION}

The pandemic has impacted the sports industry unprecedentedly. The safety protocol and international travel restrictions are strict. The games are suspended and postponed. Even many games gradually resume, most of them continue without fan attendance. The sports companies and sports leagues have to reach new deals with partners such as sponsors and broadcasting companies. They are expected to restore and sustain the business without causing widespread of virus. In such a context, data utilization becomes one of the most effective methods for them to counteract the harmful effects of the pandemic. Through data utilization, the sports companies and sports leagues can differentiate different types of customers and promote products or service to customers with personalized advertisements. Also, they can combine data with technology to provide fans with novel watching experiences and improve their engagement. And the demand for data utilization is enlarged by the fast development of the sports gambling industry. 
Participating in sports betting returns the sports companies and sports leagues with substantial sums of revenues. However, the paper's analysis of the pandemic's influences and the recommendations may be unreliable. Since the situation of the global pandemic is still unstable and may be worse in the next one or two years, its impacts on the sports industry are still uncertain. Although many sports companies and sports leagues have recovered well from the pandemic, the deterioration of the global pandemic can disrupt their plans immediately. They have to be prepared and make contingent plans for any unpleasant impacts. What's more, the context of different sports companies and sports leagues varies, for example, their political environments and epidemic control. Therefore, the recommendations may not work for all of them. They have to make plans according to their own situations and find effective ways to solve their problems. Considering the deficiencies mentioned above, the research in the future can be conducted on an area's or country's sports industry. In this way, the paper can be specific, which provides more effective and meaningful methods for the local sports companies and sports leagues.

\section{REFERENCES}

[1] Aschburner, S. (2020, December 6). NBA outlines health and safety protocols for 2020-2021 season. https://www.nba.com/news/nba-establishes-healthand-safety-protocol-for-2020-21-season

[2] CBS News. (2021, January 29). NFL teams lost almost $\$ 4$ billion in revenue due to coronavirus pandemic. https://www.cbsnews.com/news/nflpandemic-billion-revenue-loss/

[3] FISU. (2021, April 1). Chengdu 2021 FISU World University Games postponed to 2022. https://www.fisu.net/news/summer-fisu-worlduniversity-games/chengdu-2021-fisu-worlduniversity-games-postponed-to-2022

[4] MLB.com. (2021, May 7). A guide to the 2021 MLB season. https://www.mlb.com/news/what-you-needto-know-about-mlb-in-2021

[5] Mccann, M. (2020, December 30). MLS's force majeure move draws eyes to $\mathrm{CBA}$ and antitrust exemption.

Sportico. https://www.sportico.com/law/analysis/2020/mlsforce-majeure-1234619307/

[6] Holmes, B. (2021, June 9). Data shows NBA injuries up in condensed season. ESPN. https://www.espn.com/nba/story/_id/31592404/datashows-nba-injuries-condensed-season

[7] Adewunmi, M. C. \& Uroh, C. C. (2021, April 21). Psychological Impact of the COVID-19 Pandemic on Athletes. Frontiers in Sports and Active Living. https://www.frontiersin.org/articles/10.3389/fspor.20 21.603415/full

[8] Kennedy, S. (2021, March 4). Consumers Saved \$2.9 Trillion During the Pandemic. Their Money Will Drive the Global Recovery. Bloomberg. https://www.bloombergquint.com/globaleconomics/global-economic-recovery-will-bedriven-by-2-9-trillion-that-consumers-saved

[9] Barnhart, B. (2020 August 11). How to use social media in sports to keep fans engaged. Sproutsocial. https://sproutsocial.com/insights/social-media-insports/?utm_source=feedburner\&utm_medium=feed \&utm_campaign $=$ Feed $\% 3 \mathrm{~A}+$ SproutInsights $+\% 28 \mathrm{Sp}$ rout+Insights $\% 29$

[10] McCaskill, S. (2021 July 31). Sports Fans Are Ready To 'Cut The Cord' If Streaming Services Can Step Up.

Forbes.

https://www.forbes.com/sites/stevemccaskill/2021/07 /31/sports-fans-are-ready-to-cut-the-cord-ifstreaming-service-can-step-up/

[11] Stewart, C. (2021). Playing with data to win. Techradarpro.

https://www.techradar.com/news/playing-with-datato-win

[12] Parry, W. (2020 January 8). Leagues finally cash in on sports betting by selling data. AP. https://apnews.com/article/nj-state-wire-nv-statewire-sports-betting-us-news-ap-top-news$2 \mathrm{fc} 27 \mathrm{~b} 7 \mathrm{c} 558 \mathrm{ceddd} 8669 \mathrm{fb} 03 \mathrm{acc} 15 \mathrm{e} 3 \mathrm{~d}$

[13] Mccarthy, M. (2020, October 19). After Successful Tests, Sports Betting-Driven NBA Telecasts Here To Stay. Front Office Sports. https://frontofficesports.com/nba-sports-bettingstreams/

[14] Holmes, B. (2021, April 15). NBA personnel see link between compressed schedule, rash of injuries: 'We have defaulted to survival mode'. ESPN. https://www.espn.com/nba/story/_id/31258389/nbapersonnel-see-link-compressed-schedule-rashinjuries-defaulted-survival-mode 